\title{
Let's Cook, Eat, and Talk: Encouraging Healthy Eating Behaviors and Interactive Family Mealtime for an Underserved Neighborhood in Texas
}

\author{
Oak-Hee Park, PhD, RD ${ }^{1}$; Rachel Brown, $\mathrm{BS}^{2}$; Mary Murimi, PhD, RD, $\mathrm{LDN}^{3}$; \\ Linda Hoover, $\mathrm{PhD}^{4}$
}

\section{INTRODUCTION}

Family meals are associated with significant benefits including increased dietary quality, ${ }^{1-4}$ reduced risk behavior for substance abuse $\mathrm{e}^{3-5}$ and disordered eating behaviors, ${ }^{3,4}$ improved cognitive performance among children, ${ }^{3-5}$ and strengthened family connectedness. ${ }^{4,5}$ Promoting healthy eating through family meals is suggested to be an important public health strategy, but family mealfocused interventions that educate entire families are lacking. ${ }^{6}$ Furthermore, family programs that promote healthful family mealtimes through an experiential and observational learning environment for underserved families within a community setting are limited or not widely reported. The objective of Let's Cook, Eat, and Talk (LCET) was twofold: to promote healthy eating behaviors by cation and cooking classes to underserved families in the community setting and to facilitate family mealtime communication to strengthen family relationships among participants in East Lubbock, TX. providing combined nutrition edu-

\section{PROGRAM OVERVIEW}

The LCET program was part of a larger community-wide East Lubbock Promise Neighborhood grant program. To develop a culturally and socioeconomically sensitive program, the LCET research team established a community advisory board (CAB) of community leaders (eg, pastors and previous city council member), parents and teachers from schools, a foodservice program director from a food bank, nurses and doctors from the community health centers, and registered dietitian faculty from Texas Tech University in an effort to identify dietary and family communication patterns and develop a tailored intervention. The needs-based assessment through the $\mathrm{CAB}$ meetings found that a high prevalence of obesity and related chronic diseases, such as diabetes and high blood pressure, high rates of food insecurity, low accessibility to supermarkets, and low availability of fresh produce were underlying causes of the dietary habits and related chronic disease conditions in the East Lubbock community. Community advisory board

\footnotetext{
${ }^{1}$ Obesity Research Cluster, College of Human Sciences, Texas Tech University, Lubbock, TX ${ }^{2}$ Department of Nutritional Sciences, College of Human Sciences, Texas Tech University, Lubbock, TX

${ }^{3}$ Obesity Research Cluster, Department of Nutritional Sciences, College of Human Sciences, Texas Tech University, Lubbock, TX

${ }^{4}$ Obesity Research Cluster, Department of Hospitality and Retail Management, College of Human Sciences, Texas Tech University, Lubbock, TX

Conflict of Interest Disclosure: The authors have not stated any conflicts of interest.

Address correspondence to: Oak-Hee Park, PhD, RD, Obesity Research Cluster, College of Human Sciences, Texas Tech University, 1301 Akron Ave, Lubbock, TX 79409; Phone: (806) 834-0921; Fax: (806) 742-1849.; E-mail: oak-hee.park@ttu.edu

J Nutr Educ Behav. 2018;50:836-844

(C) 2018 Society for Nutrition Education and Behavior. Published by Elsevier Inc. All rights reserved.

https://doi.org/10.1016/j.jneb.2018.05.012
}

members emphasized the importance of cultivating healthy lifestyles and healthy family communication with the goal of creating a healthy environment for the individual family and the wider community.

\section{Development of the LCET Program Curriculum}

Two registered dietitian faculty members, 2 chefs from the Lubbock Chef Organization, and 1 home economics teacher developed and taught socioeconomically and culturally sensitive nutrition and cooking education content, which was based on their work experiences with underserved families from the East Lubbock community, outcomes and suggestions from the $\mathrm{CAB}$, and previous family meal literature. ${ }^{3,7-9}$ A literature review about the use of imagery for health education suggested that patients' acceptance of and adherence to health-related messages and instruction might be improved through the use of culturally relevant imagery, especially for those with lower levels of education or literacy. ${ }^{10}$ Cultural reinforcement of poor dietary behaviors combined with varying literacy levels among African American ${ }^{11}$ and Hispanic/Latino ${ }^{12}$ populations could make nutrition education and health communication challenging in underserved communities, requiring techniques beyond written and verbal instruction. Therefore, the LCET program lessons used a variety of visual aids targeted to low-income African American and Hispanic families from East Lubbock, including PowerPoint (Microsoft Corporation, Redmond, WA, Version 14.7.2, November 2010) slides with large images and video clips, food models, food packaging, poster boards, and handouts. 
The LCET program was guided by Social Cognitive Theory (SCT), which emphasizes reciprocal interactions of personal, environmental, and behavior factors to change one's behavior. ${ }^{13}$ Indeed, a previous study demonstrated the successful application of SCT to the development of a family meals-focused nutrition intervention in a community setting. ${ }^{6}$ The program facilitated adolescents' behavior changes by increasing the self-efficacy of participants, helping them to set goals associated with behavior messages and providing a family mealtime environment. Likewise, LCET sessions incorporated constructs of SCT, such as improving nutrition knowledge and self-confidence of both parents and children through nutrition and cooking lessons and activities (personal factor), providing observational and experiential learning environment by working with chefs and family members, supporting nutrition education materials (eg, MyPlate tip sheets, ${ }^{14}$ serving size cards, ${ }^{15}$ and a family cookbook ${ }^{16}$ ) for home use, and increasing outcome expectations of healthy behavior (eg, increased fruit and vegetable consumption and frequency of family dinner table conversation at home).

Nutrition and cooking lessons emphasized building skills and selfefficacy to plan, purchase, and prepare healthful meals using affordable and culturally preferred foods available locally. Based on the 2010 Dietary Guidelines for Americans ${ }^{17}$ and MyPlate, ${ }^{18}$ those lessons focused on making nutrient-dense choices from each food group in proper portion sizes while limiting added sugars, solid fats, and sodium. To facilitate the collective meal preparation, each family had its own table to cook family meals with parents and child(ren) (experiential learning); chefs helped each table by demonstrating knife skills and recipe modification methods (observational learning). To ensure sustainability, easy, economic, and popular dinner menus were selected for the family cooking lessons. The chef determined easy recipes based on the estimated active preparation time (under 30 minutes), the skill level of food preparation and knife techniques required, and the local availability and number of different ingredients used. Popularity of the menus was based on the chef's own experiences working in the East Lubbock community. Experiencing the flavors of different cuisines, such as Southwestern/Tex-Mex, Creole/ Cajun, Korean, and Chinese American, tasting a variety of seasonal fruits and vegetables, and using various forms of produce (fresh, frozen, or canned) were notable aspects of the curriculum.

Communication lessons targeted increasing dinner table conversation to strengthen family relationships. Basic knowledge of communication, listening skills, conflict resolution, and stress management were discussed, and each lesson featured soft-skill development activities, such as creating and sharing family goals posters, to practice and promote dinner table conversation both in class and at home, as well as the exclusion of electronic devices such as televisions and cell phones from the family meal setting.

The readability of content from nutrition, cooking, and communication lessons was checked by using an online program; ${ }^{19}$ the researchers determined it to be at a sixth- to eighth-grade reading level, which was recommended for public information materials according to the National Institutes of Health Plains Languages Initiatives..$^{20}$ Program feasibility (eg, family attendance) and fidelity (eg, observations of session delivery) were conducted by a registered dietitian and a trained graduate student based on the previous literature. ${ }^{21}$ Average attendance of families at each session (during program implementation) was $92 \%$; $94 \%$ of sessions were delivered as intended. The LCET team reviewed and finalized the curriculum (Table 1) and the $\mathrm{CAB}$ gave final approval for the program outline and implementation plan.

\section{EVALUATION}

A convenience sample of 45 families who lived with $\geq 1$ child (aged 8-12 years) at home at the time of recruitment was recruited from community events in the target neighborhood. Of the 45 families who intended to participate, 13 with their child(ren) $(\mathrm{n}=39 ; 13$ parents and caregivers and 26 children) took part in the LCET intervention for 4 Sundays at a community building located within the neighborhood that was equipped with lecture rooms and a commercial kitchen.

Validated survey questions from previous dietary and behavioral research $^{22-27}$ were used to assess nutrition knowledge, self-confidence about cooking, home food environment, fruit and vegetable consumption, and frequency of family dinner conversation (Table 2). Five sociodemographic questions (age, gender, highest education level, race/ethnicity, eligibility for the Supplemental Nutrition Assistance Program, the Special Supplemental Nutrition Program for Women, Infants, and Children, or both), 1 program satisfaction question (Overall, do you think this class satisfied you and your family? with a 5 -point Likert scale ranging from $1=$ very dissatisfied to $5=$ very satisfied), and 1 open-ended question (What did you like the most from the program?) were added into the questionnaire. A registered dietitian and a trained graduate student administered pre- and postsurveys before and immediately after the intervention.

After the postsurvey, a registered dietitian faculty member conducted an informal interview with the aid of a trained graduate assistant to obtain information regarding behavior changes at home and suggestions for program development. At the end of the communication lesson for week 3 , the class instructor explained the interview information and schedule to all families and collected names and available times for possible interviewees. Each interviewee was allocated 10-15 minutes in a comfortable environment and a trained graduate student collected written notes (without audio recording) for further analysis. A general inductive analysis ${ }^{28}$ was used to obtain frequent and dominant themes by categorizing interviewees' comments written in a note through careful readings, frequency of meaningful word counting, and labeling relevant words and phrases (coding). A summary of the interview results is mentioned in the Outcomes section. 
Table 1. Description of the Let's Cook, Eat, and Talk Program Curriculum

$\begin{array}{llll}\text { Lesson Type } & \text { Nutrition } & \text { Cooking (Choose 1 of 2 Menu Options) } & \text { Communication } \\ \text { Structure } & & \text { Session 2 } & \text { Session } 3 \\ \text { Session } & \text { Session 1 } & 1 \mathrm{~h} 30 \mathrm{~min} & 30 \mathrm{~min} \\ \text { Duration } & 30-40 \text { min } & \text { Commercial kitchen } & \text { Classroom } \\ \text { Place } & \text { Classroom } & \text { 2 Chefs } & 1 \text { Home economics } \\ \text { Instructor(s) } & \text { 1 Registered Dietitian } & \text { 3 Undergraduate students } & \text { teacher } \\ \text { Volunteers } & \text { 3 Undergraduate stu- } & \text { (nutrition major) } & 4 \text { Undergraduate } \\ & \text { dents (nutrition major) } & & \text { students (1 human } \\ & & & \text { development and } \\ & & & \text { family studies major } \\ & & & \text { and 3 nutrition majors) }\end{array}$

Week 1

Topics/menus Economic meal planning

Herbed Turkey Burgers, Honey BBQ Chicken

Spinach Feta Mashed Nuggets, Chili-Garlic

Potatoes, and Sum- Roasted Broccoli, and

mer Squash Sauté Roasted Corn with

Honey-Chili Butter

Objectives/cook- Create a budget and shoping skills ping list; understand and read nutrition facts labels; determine essential materials for meal plan; learn grocery shopping strategies

\begin{abstract}
Family activities/ recipe modification
\end{abstract}

\section{Compare cost per serving} of different brands and package/container sizes; make your own family shopping list using local supermarket weekly advertisement; read nutrition facts labels with children; Store versus name brand taste testing

\section{SCT constructs Nutrition knowledge} improvement, self-efficacy, reinforcement, and environment (nutrition education material support)

\section{Week 2}

Grill with low-fat meats; boil potatoes; sauté vegetables; knife skills: hold a chef's knife, peel, dice, mince, and slice; food safety for ground meats: avoid crosscontamination and check for correct internal temperature

Reduce sodium with herbs and vegetables for flavor; choose lean meats; increase dark green vegetables; choose and taste 100\% whole-wheat products (hamburger bun)

\section{Bake chicken; oven-} roast vegetables; simmer sauces; knife skills: hold a chef's knife, mince, and zest; food safety for poultry: avoid cross-contamination and check for correct internal temperature

Reduce saturated fat
and sodium content of
recipes; bake instead
of fry; choose lean
meats; substitute with
low-fat dairy products

Self-efficacy, cooking skill improvement, and environment (observational and experiential learning)

\section{Effective family communication}

Learn 4 communication styles; understand importance of family meals and communication; develop a communication ritual for dinner time and establish expectations

Introduce your family; select 2-3 topics for family dinner talks at home; create a placemat for each family member; begin making family goals poster for class presentation at the end of program

\section{Self-efficacy, reinforce- ment, environment (experiential learning such as making family goals poster), and goal setting}

\section{Ginger Salmon, Spinach and Mushroom Egg Drop Soup, and Brown/Wild Rice
Creole Catfish, Roasted Effective and active Cajun-Style Veggies, listening Whole-Wheat Roll, and Baked Stuffed Apples




\section{Table 1. (Continued)}

$\begin{array}{cl}\text { Lesson Type } & \text { Nutrition } \\ \begin{array}{c}\text { Objectives/cook- } \\ \text { ing skills }\end{array} & \text { Familiarize with MyPlate } \\ & \text { guide for healthy eating; } \\ & \text { identify } 5 \text { food groups; } \\ & \text { understand importance } \\ & \text { of balanced meals; learn } \\ & \text { about Supplemental } \\ & \text { Nutrition Assistance Pro- } \\ & \text { gram benefits }\end{array}$

$\begin{array}{ll}\begin{array}{l}\text { Family activities/ MyPlate match game; faux } \\ \text { recipe } \\ \text { modification }\end{array} & \text { food meal planning }\end{array}$

modification

\section{Cooking (Choose 1 of $\mathbf{2}$ Menu Options)}

Bake or broil fish; caramelize technique, cook with a glaze; knife skills: mince and slice; food safety for fish: check internal temperature and physical attributes for doneness

\section{Sauté, roast, and use en papillote technique for vegetables; bake or broil fish; simmer sau- ces; knife skills: mince, dice, and slice; food safety for fish: check internal temper- ature and physical attributes for doneness}

Prepare homemade, reduced-sodium soup and using a slurry; substitute with egg whites

Reduce saturated fat and sodium content of recipes; use herbs and vegetables for flavor instead of extra salt; choose $100 \%$ whole-wheat products (dinner roll)

\section{SCT constructs Nutrition knowledge improvement, self-effi- cacy, reinforcement, and environment}

\section{Week 3}

Topics/menus
Portion sizing and kitchen organization

Objectives/cooking skills

\footnotetext{
Family activities/ Plate portion sizing game; recipe modification taste fruits and vegetables with guest speaker from local farmers' market and learn about Special Supplemental Nutrition Program for Women, Infants, and Children and Farmers' Market Nutrition Program
}

\section{Recognize correct portion} and serving sizes; avoid portion distortion at home/restaurants; create efficient kitchen layout; identify place of food storage in your home

\section{Build-Your-Own Pizzas,} Sweet Potato Kale Salad, and Fruit Kebabs

Self-efficacy, cooking skill improvement, and environment (observational and experiential learning)
Knead and proof dough Bake vegetables and and bake with wholewheat products; ovenroast vegetables; knife skills: mince, dice, and slice; food safety for produce: select and store correctly, prevent crosscontamination, and identify hazardous vs nonhazardous produce items

\section{Choose and adjust} herbs to create lowsodium, low-sugar sauces at home; use vegetables and fruits from every color group; choose lean meats and meat substitutes chicken; oven-roast vegetables; purée vegetables; knife skills: dice and slice; nation and check for correct internal temperature

Reduce saturated fat recipes; use herbs vor instead of extra salt; substitute with

\section{Communication}

Learn effective listening skills and improve personal listening skills at home

\section{Easy Oven Fajitas, Black Bean and Roasted Salsa Soup, \\ Conflict resolution} food safety for poultry: avoid cross-contamiand sodium content of and vegetables for flalow-fat dairy products
Self-efficacy, reinforcement, and behavior
Family telephone game; sharing family dinner table communication experiences from past week

Engage in learning about conflict resolution through definition, causes, examples of conflicts, and problem-solving skills; learn how to resolve conflicts
Old lady/young lady optical illusion activity for seeing different perspectives 
Table 1. (Continued)

\begin{tabular}{|c|c|c|c|c|}
\hline Lesson Type & Nutrition & \multicolumn{2}{|c|}{ Cooking (Choose 1 of 2 Menu Options) } & Communication \\
\hline SCT constructs & $\begin{array}{l}\text { Nutrition knowledge } \\
\text { improvement, self- } \\
\text { efficacy, reinforcement, } \\
\text { and environment }\end{array}$ & \multicolumn{2}{|c|}{$\begin{array}{l}\text { Self-efficacy, cooking skill improvement, and } \\
\text { Environment (observational and experiential } \\
\text { earning) }\end{array}$} & $\begin{array}{l}\text { Self-efficacy and } \\
\text { reinforcement }\end{array}$ \\
\hline \multicolumn{5}{|l|}{ Week 4} \\
\hline Topics/menus & $\begin{array}{l}\text { Food safety, handling, and } \\
\text { sanitation }\end{array}$ & $\begin{array}{l}\text { Rainbow Bibimbap and } \\
\text { Sliced Watermelon }\end{array}$ & $\begin{array}{l}\text { Easy and Skinny Spicy } \\
\text { Orange Chicken, Stir- } \\
\text { Fried Vegetables, and } \\
\text { Good-For-You Fried } \\
\text { Rice }\end{array}$ & Stress management \\
\hline $\begin{array}{l}\text { Objectives/Cook- } \\
\text { ing skills }\end{array}$ & $\begin{array}{l}\text { Understand importance of } \\
\text { food safety at home } \\
\text { through learning } \\
\text { control points, personal } \\
\text { safety, prevention, } \\
\text { proper food handling, } \\
\text { and contamination } \\
\text { prevention }\end{array}$ & $\begin{array}{l}\text { Stir-fry and blanche } \\
\text { vegetables; toast ses- } \\
\text { ame seeds; advanced } \\
\text { knife skills: julienne, } \\
\text { slice on the bias, and } \\
\text { fine mince; food safety } \\
\text { for ground meats: } \\
\text { avoid cross-contami- } \\
\text { nation and check for } \\
\text { correct internal } \\
\text { temperature }\end{array}$ & $\begin{array}{l}\text { Sauté chicken; stir-fry } \\
\text { vegetables; boil rice; } \\
\text { bake casserole-style; } \\
\text { simmer homemade } \\
\text { sauces; knife skills: } \\
\text { mince, dice, and slice; } \\
\text { food safety for poultry: } \\
\text { avoid cross-contami- } \\
\text { nation and check for } \\
\text { correct internal } \\
\text { temperature }\end{array}$ & $\begin{array}{l}\text { Learn about stress and } \\
\text { its symptoms; identify } \\
\text { personal stressors; } \\
\text { reduce stress through } \\
\text { coping methods and } \\
\text { exercise }\end{array}$ \\
\hline $\begin{array}{l}\text { Family activities/ } \\
\text { recipe } \\
\text { modification }\end{array}$ & $\begin{array}{l}\text { Effective hand washing } \\
\text { with germ detection pow- } \\
\text { der test; hazardous food } \\
\text { detective game with } \\
\text { model foods }\end{array}$ & $\begin{array}{l}\text { Reduce saturated fat } \\
\text { content of recipe; pre- } \\
\text { pare a marinade and } \\
\text { adjust sodium, sugar } \\
\text { content, and flavor; } \\
\text { use a variety of vege- } \\
\text { table colors and types } \\
\text { for flavor }\end{array}$ & $\begin{array}{l}\text { Reduce saturated fat } \\
\text { and sodium content of } \\
\text { recipes; sauté and } \\
\text { bake instead of fry; } \\
\text { substitute with whole- } \\
\text { grain ingredients }\end{array}$ & $\begin{array}{l}\text { 2-min relaxation exer- } \\
\text { cises; crumple up } \\
\text { your cares trash can } \\
\text { toss game; present } \\
\text { family goals poster } \\
\text { (with photos, recipes, } \\
\text { and dinner topics from } \\
\text { past weeks) }\end{array}$ \\
\hline SCT constructs & $\begin{array}{l}\text { Nutrition knowledge } \\
\text { improvement, self-effi- } \\
\text { cacy, reinforcement, and } \\
\text { environment }\end{array}$ & $\begin{array}{l}\text { Self-efficacy, cooking ski } \\
\text { environment (observati } \\
\text { learning) }\end{array}$ & $\begin{array}{l}\text { improvement, and } \\
\text { nal and experiential }\end{array}$ & $\begin{array}{l}\text { Self-efficacy, reinforce- } \\
\text { ment, environment } \\
\text { (experiential learning), } \\
\text { outcome expecta- } \\
\text { tions, and goal setting } \\
\text { (for healthful family } \\
\text { meal practices for the } \\
\text { future) }\end{array}$ \\
\hline
\end{tabular}

SCT indicates Social Cognitive Theory.

\section{OUTCOMES}

Table 3 lists demographic characteristics of participants. A total of $92 \%$ of participants were satisfied with the program (mean $\pm \mathrm{SD}=4.38 \pm$ 0.65). Cooking with professional chefs, learning how to make healthy dishes from different cultures, learning and practicing portion sizing, and practicing communication at the family table were the most satisfactory components of the program.

Nonparametric Wilcoxon matched pair test $(2$-tailed at $P<.05)$ revealed that adult participants' total nutrition knowledge improved significantly $(P=.007)$, especially regarding portion sizing $(P=.02)$ and MyPlate $(P=.004)$. Frequency of family dinner conversation improved but not significantly $(P=.08)$. However, scores for self-confidence about cooking, home food environment, and fruit and vegetable consumption did not improve.

Eight parents and caregivers participated in an informal interview. Most participants $(n=7)$ expressed that their families had fun during the program, that activities from the
LCET lessons helped with shopping and food preparation at home, that they tried to check nutrition and product labels during grocery shopping, and that their families had dinner table conversation every week while participating in the program. Three caregivers also mentioned that their families tried to eat more fresh fruits as desserts and vegetables as side dishes, and their children were more engaged in helping with meal preparation at home. Furthermore, they were motivated to try healthier recipes and foods from other cultures such as fresh spring rolls. In the 
Table 2. Description of Survey Variables Based on Social Cognitive Theory Constructs

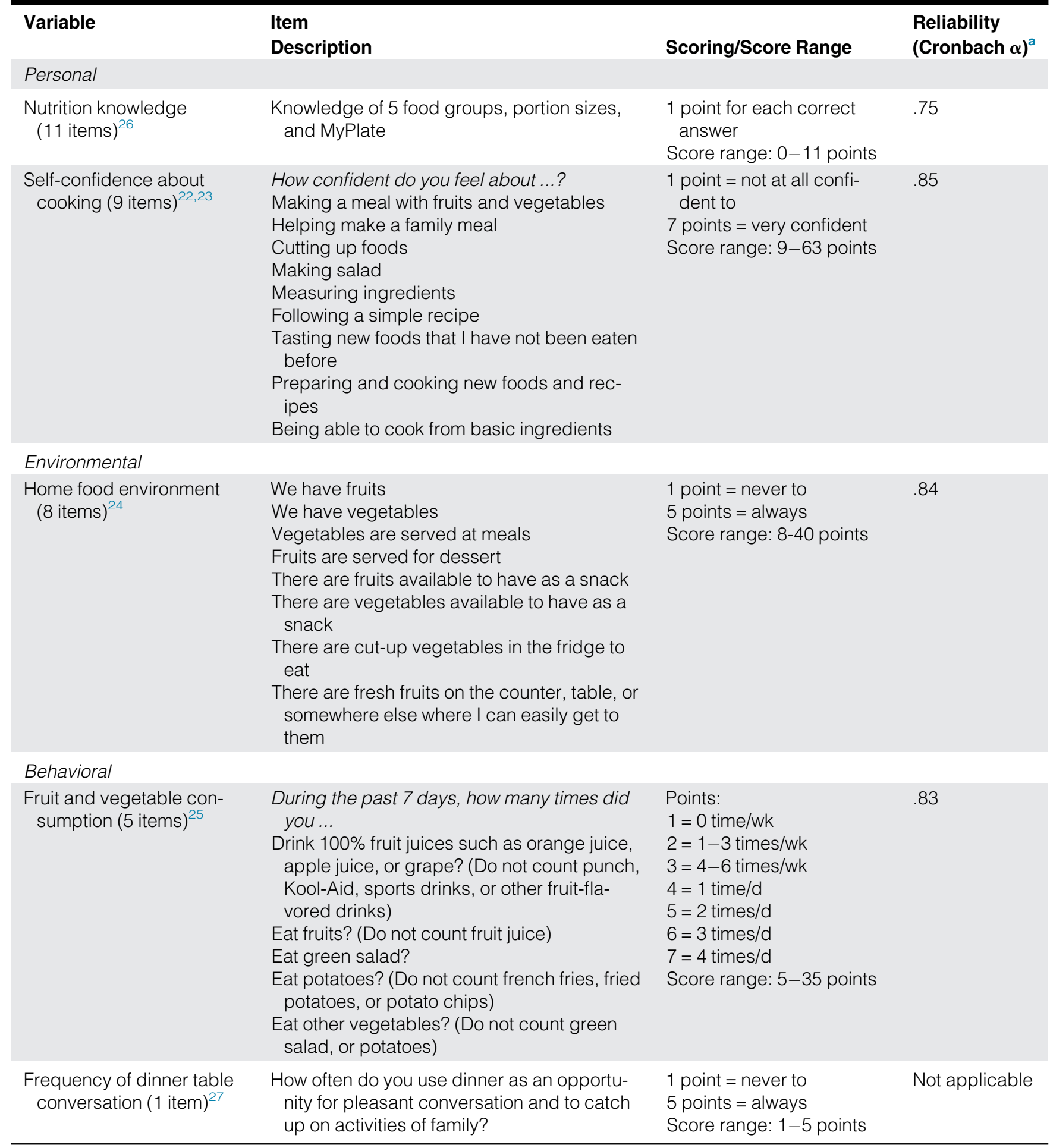

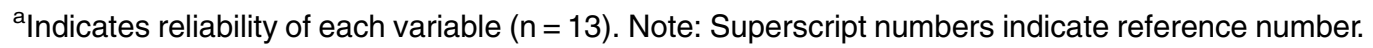


Table 3. Demographic Characteristics of Adult Participants (Parents/Caregivers $[n=13])$

$\begin{array}{lll}\text { Characteristics } & \text { Mean/Frequency } & \text { Valid (\%) } \\ \text { Age, y (mean) } & 40.15 & \text { Not applicable } \\ \text { Gender } & 3 & 23.1 \\ \quad \text { Male } & 10 & 76.9 \\ \quad \text { Female } & & \\ \text { Ethnicity } & 6 & 46.2 \\ \text { African American } & 6 & 46.2 \\ \text { Hispanic } & 1 & 7.6 \\ \text { Others } & 1 & 7.7 \\ \text { Highest education level } & 8 & 61.5 \\ \text { Middle school } & 3 & 23.1 \\ \text { High school } & 1 & 7.7 \\ \text { Some college } & & 23.1 \\ \text { College degree or higher } & & \\ \text { Eligibility for Supplemental } & & \\ \text { Nutrition Assistance Program } & & \\ \text { and/or Special Supplemental } & & \\ \text { Nutrition Program for Women, } & & \\ \text { Infants, and Children } & & \\ \text { Yes } & & \end{array}$

interview, 2 elderly adults (aged $>60$ years) expressed an increased desire to learn and follow nutritional recommendations for chronic disease prevention and management, especially related to diabetes and cancer. However, most participants $(n=7)$ stressed that their limited budgets, time constraints, family cooking preferences (such as frying), and poor local food environment were still barriers. Participants' perceived barriers to healthy eating behaviors were similar to those reported by adults in other underserved African American and Hispanic/Latino communities in the US. The poor local food environment (eg, cost, accessibility, and quality of produce), ${ }^{29-37}$ time constraints or the inconvenience of preparing healthy foods or produce, ${ }^{29,32,33,36}$ and the influence of family cooking preferences ${ }^{33-36}$ were challenges that were found in other underserved communities as well, especially as barriers to fruit and vegetable consumption. However, in some research studies, family cooking preferences and practices, especially during upbringing, were instead mentioned as promoters of fruit and vegetable consumption for both African American and Hispanic/ Latino families. ${ }^{29,32}$

\section{APPLICATION}

The LCET program offered an interactive family-oriented nutrition education that reflected some of the neighborhood's needs and culture to increase understanding of healthy eating habits and communication skills for families in the community. In East Lubbock, the LCET curriculum was successful in increasing nutrition knowledge of program participants, which might help those underserved families transition to healthier eating practices and provide them with tools to improve family meal frequency and connectedness. Through partnerships with community organizations, the program might be transformed and sustained continuously, a process that is under way in East Lubbock by incorporating a local food bank.

This study had limitations. Significant improvement in nutrition knowledge of the participants was confirmed after the program delivery, but the scores for self-confidence about cooking, home food environment, and fruit and vegetable consumption did not improve. The applicability of this program to similar populations is unknown because the results were based on a small convenience sample for both the program survey $(n=13)$ and interviews $(n=8)$. Although the program setting encouraged parents (and/or chefs in cooking lessons) to help their children to learn concepts from all lessons, the average readability of the content was at the sixth- through eighth-grade level, which was high for some children who were under the sixth grade in the intervention. To reduce this variation, trained undergraduate volunteers (who were majoring in nutrition and human development and family studies) supported families' needs in the class to enhance children's learning appropriate for their age and also facilitate family meal preparation. Although the LCET program was well received in East Lubbock, the feasibility of using this program with other populations has not been demonstrated. In addition, none of the participants shared their least favorite program components or suggestions for change. From the informal interview, interviewees might have wished to be courteous to the interviewer, which may have skewed self-reported results. Because most interviewees $(n=7)$ reported that their families had dinner table conversation every week while participating in the program, the program may have met its objective of increased conversation at family mealtime. However, this result was based on participants' selfreport and may have been biased as well. For future studies, a qualitative assessment from both parents and children to explain significant barriers for healthy behavior and longitudinal study design to follow-up behavior changes after intervention will enhance the quality of interventions similar to LCET.

\section{NOTES}

Institutional review board approval for this LCET program was obtained by the Human Research Protection 
Program at Texas Teach University. A copy of education materials is available by contacting the corresponding author. This program is a part of the East Lubbock Promise Neighborhood Grant program funded by the US Department of Education (Grant No. U215N120013).

\section{REFERENCES}

1. Fulkerson JA, Larson N, Horning M, Neumark-Sztainer D. A review of associations between family or shared meal frequency and dietary and weight status outcomes across the lifespan. J Nutr Educ Behav. 2014;46: 2-19.

2. Larson N, Fulkerson J, Story M, Neumark-Sztainer D. Shared meals among young adults are associated with better diet quality and predicted by family meal patterns during adolescence. Public Health Nutr. 2013;16:883-893.

3. Neumark-Sztainer D, Larson NI, Fulkerson JA, Eisenberg ME, Story M. Family meals and adolescents: what have we learned from Project EAT (Eating Among Teens)? Public Health Nutr. 2010;13:1113-1121.

4. Fruh SM, Fulkerson JA, Mulekar MS, Kendrick LAJ, Clanton C. The surprising benefits of the family meal. $J$ Nurse Pract. 2011;7:18-22.

5. Eisenberg ME, Olson RE, NeumarkSztainer D, Story M, Bearinger LH. Correlations between family meals and psychosocial well-being among adolescents. Arch Pediatr Adolesc Med. 2004;158:792-796.

6. Flattum C, Draxten M, Horning M, et al. HOME Plus: Program design and implementation of a family-focused, community-based intervention to promote the frequency and healthfulness of family meals, reduce children's sedentary behavior, and prevent obesity. Int J Behav Nutr Phys Act. 2015;12:53.

7. Golan M, Weizman A. Familial approach to the treatment of childhood obesity: conceptual model. J Nutr Educ. 2001;33:102-107.

8. Fulkerson JA, Story M, NeumarkSztainer D, Rydell S. Family meals: perceptions of benefits and challenges among parents of 8- to 10-year-old children. J Am Diet Assoc. 2008;108: 706-709.

9. Elgar FJ, Craig W, Trites SJ. Family dinners, communication, and mental health in Canadian adolescents. $J$ Adolesc Health. 2013;52:433-438.

10. Houts PS, Doak CC, Doak LG, Loscalzo MJ. The role of pictures in improving health communication: a review of research on attention, comprehension, recall, and adherence. Patient Educ Couns. 2006;61:173-190.

11. Houts PS, Shankar S, Klassen AC, Robinson EB. Use of pictures to facilitate nutrition education for lowincome African American women. $J$ Nutr Educ Behav. 2006;38:317-318.

12. Elder JP, Ayala GX, Parra-Medina D, Talavera GA. Health communication in the Latino community: issues and approaches. Annu Rev Public Health. 2009;30:227-251.

13. Bandura A. Social Foundations of Thought and Action: A Social Cognitive Theory. Englewood Cliffs, NJ: Prentice-Hall; 1986.

14. US Department of Agriculture. 10 tips: Choose MyPlate. https://www.choosemyplate.gov/ten-tips-choose-myplate. Accessed June 14, 2018.

15. National Heart, Lung, and Blood Institute. NHLBI serving size card. https:// www.nhlbi.nih.gov/health/educational/ wecan/downloads/servingcard7.pdf. Accessed June 14, 2018.

16. Maulding M. Eat Right for Less: Nutrition on a Budget. West Lafayette, IN: Purdue University; 2010.

17. US Department of Agriculture and US Dept of Health and Human Services. Dietary Guidelines for Americans, 2010. 7th ed. Washington, DC: US Government Printing Office; 2010.

18. US Department of Agriculture. ChooseMyPlate.gov. https://www.choosemyplate.gov/MyPlate. Accessed June 14, 2018

19. Child D, Colmer R, Linney S. Readable.io. https://readable.io/. Accessed June 14, 2018.

20. Carbone ET, Zoellner JM. Nutrition and health literacy: a systematic review to inform nutrition research and practice. $J$ Acad Nutr Diet. 2012;112:254-265.

21. Baranowski T, Cerin E, Baranowski J. Steps in the design, development and formative evaluation of obesity prevention-related behavior change trials. Int $J$ Behav Nutr Phys Act. 2009;6:6.

22. Barton KL, Wrieden WL, Anderson AS. Validity and reliability of short questionnaire for assessing the impact of cooking skills interventions. J Hum Nutr Diet. 2011;24:588-595.

23. Woodruff SJ, Kirby AR. The associations among family meal frequency, food preparation frequency, self-efficacy for cooking, and food preparation techniques in children and adolescents. J Nutr Educ Behav. 2013;45:296-303.

24. Robinson-O'Brien R, NeumarkSztainer D, Hannan PJ, Burgess-Champoux T, Haines J. Fruits and vegetables at home: child and parent perceptions. $J$ Nutr Educ Behav. 2009;41:360-364.

25. Centers for Disease Control and Prevention. Surveillance of fruit and vegetable intake using the behavioral risk factor surveillance system. https://www.cdc. gov/brfss/pdf/fruits_vegetables.pdf. Accessed June 14, 2018.

26. US Department of Agriculture. Team Nutrition: My Plate. http://www.fns. usda.gov/tn/myplate. Accessed June 14,2018

27. Hillaker BD, Brophy-Herb HE, Villarruel FA, Haas BE. The contributions of parenting to social competencies and positive values in middle school youth: positive family communication, maintaining standards, and supportive family relationships. Fam Relat. 2008;57: 591-601.

28. Thomas DR. A general inductive approach for analyzing qualitative evaluation data. Am J Eval. 2006;27:237-246.

29. Lucan SC, Barg FK, Karasz A, Palmer CS, Long JA. Perceived influences on diet among urban, low-income African Americans. Am J Health Behav. 2012;36:700-710

30. Zenk SN, Odoms-Young AM, Dallas C, et al. "You have to hunt for the fruits, the vegetables": environmental barriers and adaptive strategies to acquire food in a low-income African American neighborhood. Health Educ Behav. 2011;38:282-292.

31. Fulp RS, McManus KD, Johnson PA. Barriers to purchasing foods for a highquality, healthy diet in a low-income African American community. Fam Community Health. 2009;32:206-217.

32. Yeh MC, Ickes SB, Lowenstein LM, et al. Understanding barriers and facilitators of fruit and vegetable consumption among a diverse multi-ethnic population in the USA. Health Promot Int. 2008;23:42-51.

33. Ayala GX, Elder JP, Campbell NR, et al. Nutrition communication for a Latino community: formative research foundations. Fam Community Health. 2001;24:72-87.

34. Evans A, Chow S, Jennings R, et al. Traditional foods and practices of Spanish-speaking Latina mothers 
influence the home food environment: implications for future interventions. $J$ Am Diet Assoc. 2011;111:1031-1038.

35. Swierad EM, Vartanian LR, King M. The influence of ethnic and mainstream cultures on African Americans' health behaviors: a qualitative study. Behav Sci (Basel). 2017;7:49.

36. Baruth M, Sharpe PA, Parra-Medina D, Wilcox S. Perceived barriers to exercise and healthy eating among women from disadvantaged neighborhoods: results from a focus groups assessment. Women Health. 2014;54:336-353.

37. Rowe J. Voices from the inside: African American women's perspectives on healthy lifestyles. Health Educ Behav. 2010;37:789-800.

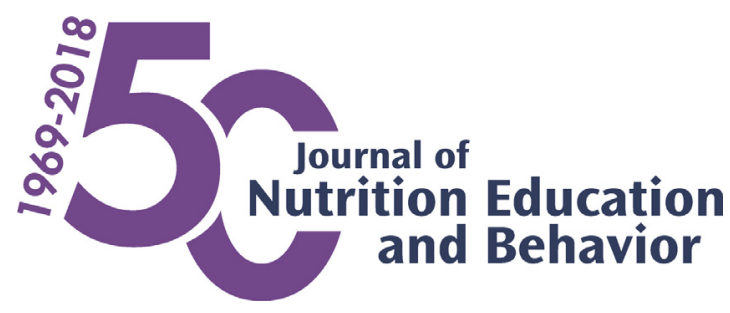

"Like" and "Follow"

JNEB to receive updates on:

- New Article Collections

- Educational Webinars

- Calls for Papers

- Author Podcasts and more...

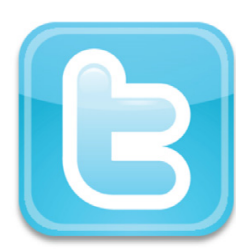

https://twitter.com/JNEBonline

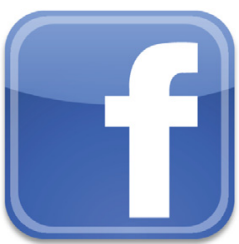

https://www.facebook.com/JNEBorg/ 